\title{
Winter mortality modifies the heat-mortality association the following summer
}

\author{
J. Rocklöv, B. Forsberg and K. Meister
}

\begin{abstract}
The present study aimed to investigate how the heat-related increase in deaths in summer and the extent of mortality displacement depend on influenza and other categories of mortality in the previous winter, which when low leaves a greater pool of susceptible individuals.

Mortality data from Stockholm, Sweden, from 1990-2002 were stratified into a summer period and a winter period. A Poisson regression model was established for the daily mortality in the summer, with temperature and confounders as explanatory variables. In addition, indicators of total, respiratory, cardiovascular and influenza mortality of the winter period were incorporated as effect modifiers in the summer model, and lagged effects in strata defined by indicators were studied.
\end{abstract}

A high rate of respiratory as well as cardiovascular mortality in winter reduced the heat effect the following summer, and influenza mortality tended to do so as well. The cumulative effect per C increase was $0.95 \%$ below and $0.89 \%$ above a threshold $\left(21.3^{\circ} \mathrm{C}\right)$ after a winter with low cardiovascular and respiratory mortality, but $-0.23 \%$ below and $0.21 \%$ above the threshold after a winter with high cardiovascular and respiratory mortality.

The current study shows that high respiratory, cardiovascular and influenza mortality in winter leads to lower temperature effects in the following summer. It also suggests that persons for whom influenza may be fatal are often also susceptible to heat and this subgroup might, therefore, not benefit as much as expected from influenza vaccinations.

KEYWORDS: Cardiovascular disease, elderly, influenza, mortality, respiratory disease, temperature

nterest in heat effects on mortality increased dramatically in Europe after the severe heatwave in 2003, and it has been further intensified by the growing interest in climate change and adaptation [1-4]. Longitudinal studies assessing the risks of high ambient temperature on population-level mortality traditionally incorporate time-series analysis or heat-episode analysis. A detailed review on the topic was published in 2002 by BASU and SAMET [5]. Most of the excess mortalities are cardiovascular and respiratory deaths and occur among older persons [5]. Therefore, heat exposure is sometimes followed by a variable proportion of deaths brought forward in time, referred to as mortality displacement. However, the evidence and the extent of mortality displacement during heat exposure are not consistent [6-14]. In the present study of Greater Stockholm (Sweden), the current authors investigated how displacement of mortality during the cold season, leaving a smaller pool of fragile individuals, affects the populationlevel risks of heat-related mortality in the following summer.
A common and accepted way to estimate mortality displacement is by using distributed lag models [15]. However, for longer-term distributed lag analysis, displacement of mortality is less pronounced and harder to estimate due to seasonal patterns in mortality rates. Hence, one major problem with studies assessing the risks of temperature on mortality is the estimation of longer-term time-scale mortality displacement.

Great variations in excess mortality levels caused by the 2003 heatwaves were observed in France, even between regions closely situated and with quite similar meteorological conditions [16]. A general reduction of the mortality level was observed in the following years, as well as lower excess mortality during the heatwave of 2006 [17]. However, it should be mentioned that these occurrences can be explained not only by the high excess mortality in 2003 , but also by general deficits in mortality and a functioning heatwave warning system during 2006. Few previously published papers in this field have discussed the nonrandom reasons for yearly variations in the effect of heat on mortality as relative risk
AFFILIATIONS

Institution of Occupational and Environmental Medicine, Dept of Public Health and Clinical Medicine, Umeå University, Umeå, Sweden.

CORRESPONDENCE

J. Rocklöv

Occupational and Environmental Medicine

Umeå University

90187 Umeå

Sweden

Fax: 46907852456

E-mail: joacim.rocklov@

envmed.umu.se

Received:

March 112008

Accepted after revision:

September 032008

\section{SUPPORT STATEMENT}

This study received funding through

the Swedish climate adaptation

research programme, Climatools

(Stockholm, Sweden).

STATEMENT OF INTEREST

None declared. 
estimates. Some have hypothesised that the variation depends on the extent of mortality in previous months or previous winter season, which when mild leaves a larger pool of susceptible individuals [2, 18-20].

To investigate variation in the risk coefficients between summers and to address the dependency of heat-effect estimates on previous winter mortality, the current authors studied the yearly variation in relative risk estimates, and the modification of the summer heat effect by different indicators of mortality during the previous winter. The indicators used are total (excluding external causes) mortality, respiratory mortality, cardiovascular mortality, influenza mortality and cardiovascular plus respiratory mortality. Moreover, since this hypothesis implies that the pool of fragile individuals varies between years, some of the inconsistency in the extent of harvesting might also be explained. To investigate and compare harvesting between two categories of summers as defined by the indicators, lag-stratified distributed lag models were established.

\section{METHODS \\ Data}

The Swedish capital Stockholm is situated on the coast and has rather mild winters due to the Atlantic influence on Scandinavia and experiences only moderate heat in summer. The current authors studied Greater Stockholm, with a population of 1.1-1.45 million over the period 1990-2002. Cause-specific mortality data were provided by the Swedish National Board of Health and Welfare. The daily rates of allcause mortality in all ages, excluding violent deaths (according to the International Classification of Diseases (ICD) ninth revision before 1997 (ICD-9) and tenth from 1997 (ICD-10)), daily rates of influenza mortality (ICD-9:487 and ICD-10:J1011), daily rates of cardiovascular mortality (ICD-9:390-459 and ICD-10:I), daily rates of respiratory mortality (ICD-9:460-519 and ICD-10:J) and daily rates of cardiovascular plus respiratory mortality (ICD-9:390-519 and ICD-10:I-J) were considered.

For the same period, daily data on temperature, relative humidity $(\mathrm{RH})$ and air pollution in Stockholm were received from the Environment and Health Administration in Stockholm. The daily mean temperature was missing for 96 days during the study period, with the majority of days (57) in 1992. The daily mean $\mathrm{RH}$ was missing for 34 days. Missing values were not imputed.

Data were stratified on a seasonal basis into a summer period, June-August, and a winter period, October-April.

\section{Statistical analysis}

Modelling approach

Daily counts of all-cause mortality during summer were assumed to follow an overdispersed Poisson distribution. From previous analyses of Stockholm data it was known that a generalised additive model (GAM) would fit the data well [21]. Smooth functions of penalised cubic splines were used to describe within-summer seasonal variation and longer-term time trend, and a priori assumptions were made for their maximum degrees of freedom (df). The within-summer seasonal variation was assumed to be the same for all years and explained the variation in mortality not explained by temperature. The smooth function describing the trend over the study period was allowed $1 \mathrm{df}$ for every four summers, and the smooth function of within-seasonal variation was allowed $1 \mathrm{df}$ per month. The sensitivity of the a priori assumptions was tested by doubling the df for each smooth function.

Weather variables were fitted using smooth penalised spline functions as a first approach, and then estimated by linear terms if suitable. Daily mean, maximum and minimum temperatures were modelled in the first stage, and then only the optimal predictor based on the generalised cross validation (GCV) score was proceeded with. The optimal lag structure for temperature based on GCV score was determined using moving averages (MAs). RH (centred), oxides of nitrogen and ozone were included as the daily mean. It was decided $a$ priori that humidity and air pollutants were to be kept in the models if their $\mathrm{p}$-values were $<0.1$.

A threshold in the effect of mortality was estimated using maximum likelihood of the 2-day mean $\left(\mathrm{MA}_{1}\right)$ of temperature, and a model was fitted with a piecewise linear temperature component according to this threshold. The breakpoint was also clearly apparent in the smooth function of temperature estimated in previous steps. Moreover, yearly coefficients for the temperature effect were estimated on both sides of the threshold and a least squares weighted regression (with the inverse of the variance of the yearly estimates as weights) was fitted in order to estimate the trend over the study period.

\section{Winter mortality}

Five different dichotomous indicators for the previous winter season mortality were used in the analysis. The variables used to define those indicators were winter cumulative total mortality, winter cumulative respiratory mortality (RES), winter cumulative cardiovascular mortality (CVD), winter cumulative influenza mortality (INF) and winter cumulative cardiovascular plus respiratory mortality (CVD+RES). First, the underlying winter variables of daily mortality were tested for time trend and no statistically significant influence of time was found, with the exception of cardiovascular winter mortality, which significantly declined during the period. Secondly, the variables were stratified into low and high levels by constraining each one of them to have at least five and at most seven observations per level. The greatest distance between the ordered observations fulfilling this constraint was identified and they were stratified thereafter into the two categories. The stratification can be seen in table 1 , where " $\mathrm{H}^{\prime}$ symbolises a high level and " $\mathrm{L}$ " symbolises a low level of winter mortality. When incorporating the indicators as effect modifiers of the following summer's temperature effects in the model, it was assumed that changes in the yearly summer mean mortality were explained by the smooth function describing long-term time trend.

The final Poisson GAM model estimating the effect modification of the extent of previous winter mortality in influenza on the summer heat effect can be described as follows, where $Y_{t}$ denotes the daily mean number of all-cause deaths (excluding external causes) on day $t, \alpha$ denotes the logarithm of the expected counts at baseline, $\beta_{0}$ denotes the log relative risk associated with a $1^{\circ} \mathrm{C}$ increase in temperature below the threshold for the low strata of INF, $\beta_{1}$ denotes the effect modification of $\log$ relative risk associated with a $1^{\circ} \mathrm{C}$ increase 
TABLE 1 Cumulative mortality and weather data for the winter and summer seasons

\begin{tabular}{|c|c|c|c|c|c|c|c|c|c|c|}
\hline \multicolumn{5}{|c|}{ Winter (October-April) } & \multicolumn{6}{|c|}{ Summer (June-August) } \\
\hline Year & тот & RES & INF & CVD & Year & Deaths & $\begin{array}{c}\text { Mean temp } \\
{ }^{\circ} \mathrm{C}\end{array}$ & $\begin{array}{c}\text { Min temp } \\
{ }^{\circ} \mathrm{C}\end{array}$ & $\begin{array}{c}\text { Max temp } \\
{ }^{\circ} \mathrm{C}\end{array}$ & $\begin{array}{c}\text { Mean RH } \\
\%\end{array}$ \\
\hline 1990/91 & $8855(\mathrm{H})$ & $758(\mathrm{~L})$ & $11(\mathrm{~L})$ & 4495(H) & 1991 & 3580 & 17.0 & 6.4 & 30.0 & 70 \\
\hline 1991/92 & $8750(L)$ & $785(\mathrm{H})$ & $19(\mathrm{~L})$ & $4329(\mathrm{H})$ & 1992 & 3396 & 16.0 & 7.3 & 27.0 & 62 \\
\hline 1994/95 & $8534(L)$ & 728(L) & $6(\mathrm{~L})$ & $4127(L)$ & 1995 & 3468 & 17.2 & 8.7 & 28.7 & 63 \\
\hline 1995/96 & 9102(H) & $859(H)$ & $36(\mathrm{H})$ & $4318(H)$ & 1996 & 3357 & 16.4 & 8.6 & 27.5 & 63 \\
\hline 1996/97 & $9086(\mathrm{H})$ & $808(H)$ & $33(\mathrm{H})$ & $4274(\mathrm{H})$ & 1997 & 3390 & 18.7 & 6.3 & 29.1 & 63 \\
\hline 1997/98 & $8720(L)$ & $720(L)$ & $43(\mathrm{H})$ & $4138(L)$ & 1998 & 3463 & 14.5 & 6.5 & 25.4 & 73 \\
\hline 1998/99 & 9022(H) & $757(\mathrm{~L})$ & $58(\mathrm{H})$ & $4156(L)$ & 1999 & 3476 & 17.8 & 8.9 & 30.8 & 68 \\
\hline 1999/00 & $9114(\mathrm{H})$ & 789(H) & $62(\mathrm{H})$ & $4092(\mathrm{~L})$ & 2000 & 3379 & 15.6 & 7.2 & 25.2 & 75 \\
\hline
\end{tabular}

in temperature below the threshold for the high strata of INF, $\beta_{2}$ denotes the log relative risk associated with a $1^{\circ} \mathrm{C}$ increase in temperature above the threshold for the low strata of INF, $\beta_{3}$ denotes the effect modification of log relative risk associated with a $1{ }^{\circ} \mathrm{C}$ increase in temperature above the threshold for the high strata of INF, $\beta_{4}$ denotes the log relative risk associated with a $1 \%$ increase in $\mathrm{RH}, \beta_{5 \mathrm{i}}$ denotes the log relative risk associated with day of week (with i taking all values from 1 to 6), $\beta_{6}$ denotes the log relative risk associated with calendar holidays and $S_{1}$ and $S_{2}$ are smooth functions describing withinyear variation (season) and long-term time trend, with specified maximum df, respectively.

$\mathrm{Y}_{\mathrm{t}} \sim \operatorname{Poisson}\left(\mu_{\mathrm{t}}\right)$

$\log \left(\mu_{\mathrm{t}}\right)=\alpha+\beta_{0} \mathrm{MA}_{1}\left(\mathrm{~T}_{\mathrm{t}, \mathrm{T}<\text { Threshold }}\right)+\beta_{1} \mathrm{MA}_{1}\left(\mathrm{~T}_{\mathrm{t}, \mathrm{T}<\text { Threshold }}\right) \cdot \mathrm{INF}_{\mathrm{t}}$ $+\beta_{2} \mathrm{MA}_{1}\left(\mathrm{~T}_{\mathrm{t}, \mathrm{T}} \geqslant\right.$ Threshold $)+\beta_{3} \mathrm{MA}_{1}\left(\mathrm{~T}_{\mathrm{t}, \mathrm{T} \geqslant \text { Threshold }}\right) \cdot \mathrm{INF}_{\mathrm{t}}+\beta_{4} \mathrm{RH}_{\mathrm{t}}+$ $\beta_{5 i}$ Weekday $_{t}+\beta_{6}$ Holiday $_{t}+S_{1}\left(\right.$ Season $\left._{t}, 3\right)+S_{2}\left(\right.$ Trend $\left._{t}, 3\right)$

Furthermore, the data were stratified on a yearly basis by the effect modification variable CVD+RES, and a constrained distributed lag analysis was applied to each stratum. In the distributed lag model, three lag variables were defined: lag 0 1, lag 2-6 and lag 7-13. The mean temperature for each was used as an explanatory variable. To calculate the distributed lags separately for high and low temperatures and to simplify interpretation of the cumulative effects, the 2-day mean threshold was employed as breakpoint in all lag strata. The structure of the lag stratification was chosen a priori $[15,21]$.

The effect estimates (relative risks) are presented as percentage per ${ }^{\circ} \mathrm{C}$ increase in temperature, with $95 \%$ confidence intervals (CIs).

\section{RESULTS}

In table 1, the mortality rates for the studied winter and summer periods are presented, with some additional weather statistics for the summers. The 48 -h mean temperature was found to be the optimal predictor of daily mortality in June-August according to the GCV score; however, little difference was found between the performance of maximum, minimum and mean temperature as predictors. Figure 1 describes the log of risk relative to the overall summer mean temperature of the study period for 2-day mean temperatures in summer. The estimated threshold for the temperature-mortality relationship approximately corresponded to the 90th percentile of the 2-day mean summer temperature, $21.3^{\circ} \mathrm{C}\left(95 \% \mathrm{CI} 20.0-22.9^{\circ} \mathrm{C}\right)$.

In figure 2, the estimated year-specific linear modelled effects for temperature below and above the threshold are shown. The risk estimates increased with time on both sides of the threshold, even though a long-term time trend in mortality

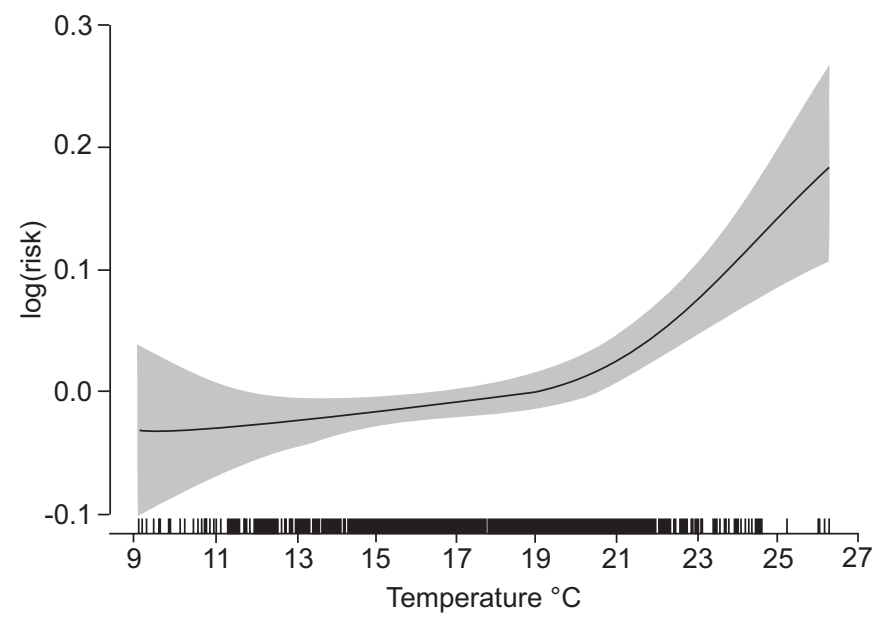

FIGURE 1. Smooth function describing the impact of 2-day mean temperatures on total mortality (excluding external causes) in summer. 1 : $95 \%$ confidence interval. Black lines below graph indicate inclusion of corresponding temperatures within the data set. 

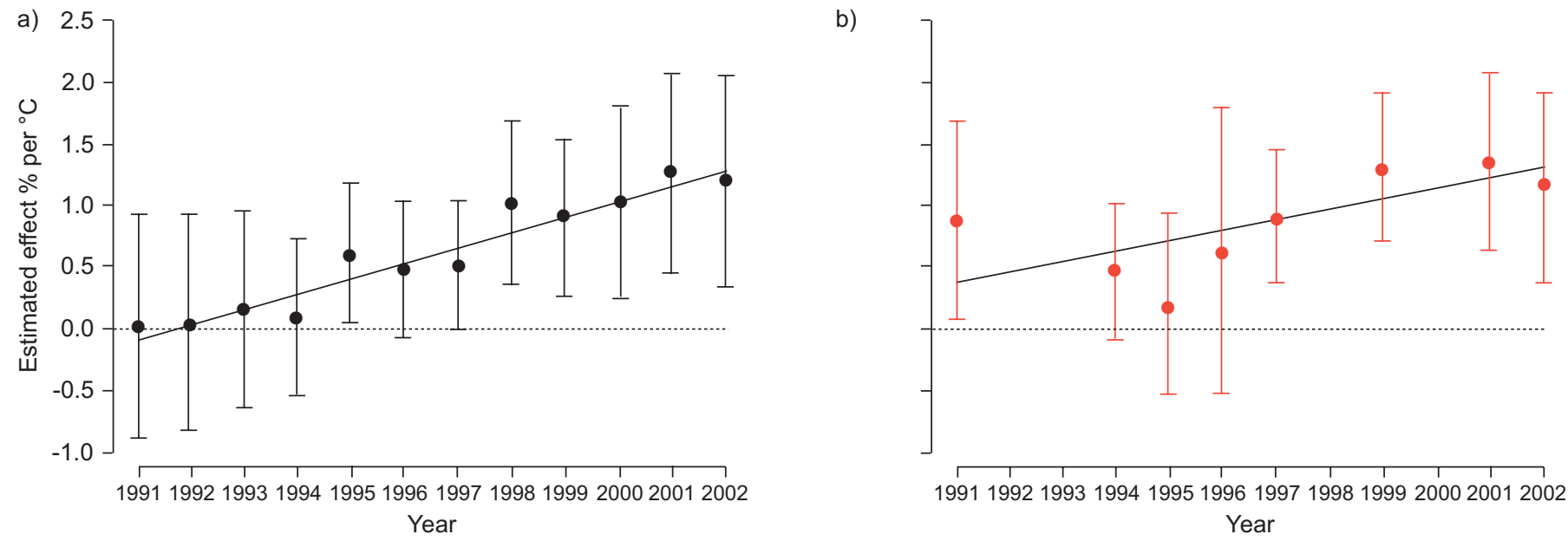

FIGURE 2. Yearly effect estimates for each summer with year-specific $95 \%$ confidence intervals a) below and b) above the threshold at the 90 th percentile of 2 -day mean summer temperatures. The regression lines are the weighted least squares fit, with weights equal to the inverse of the variance of the estimates at each year. Too few observations above the threshold made the effect estimation impossible during four of the years.

was controlled for in the model. Without a threshold, the only effect estimate that was not statistically significant was for the summer of 1992, which had the majority of missing values. The weighted least squares fit of the yearly effects for temperature resulted in a statistically significant increase of 0.13 units $\cdot \mathrm{yr}^{-1}$ (95\% CI 0.10-0.15) below the 90th percentile and 0.09 units $\cdot \mathrm{yr}^{-1}$ (95\% CI 0.02-0.15) above the threshold.

Table 2 shows the estimated effects of temperature and $\mathrm{RH}$ and the effect modification of the indicators for the piecewise linear models with threshold. The effect modification of the indicators for respiratory as well as for cardiovascular winter mortality on the temperature effect is statistically significant below the threshold, and reduces the effect of temperature in summers when respiratory or cardiovascular mortality in the previous winter was high. Moreover, the modifying effect of the indicator for influenza in winter is borderline significant below the threshold $(p=0.058)$. However, there is little effect modification by the total mortality in the previous winter season. Moreover, a statistically significant linear effect of the daily mean RH was found, as shown in table 2 , but no significant interaction was observed in the model for temperature and $\mathrm{RH}$. The effect of
$\mathrm{RH}$ seemed rather immediate, corresponding to a moving average of lag 0 according to the GCV score.

In figure 3, estimates of the lag-stratified effects in three lag strata above and below the threshold $\left(21.3^{\circ} \mathrm{C}\right)$ are shown. Furthermore, in figure 4, the lag-stratified distributed lags of temperature for groups classified by the indicator for respiratory plus cardiovascular winter mortality are presented. If apparent, short time-mortality displacement could be seen as a lagged negative effect. In the all-years distributed lag effects above and below the threshold, there was a rather pronounced immediate (lag 0-1) increase in mortality followed by a weak negative effect the week after. However, if winter mortality was higher, the lag structure of the effect of heat was somewhat different from when winter mortality was lower, revealing a more delayed effect of heat in the years with higher winter mortality (fig. 4).

All of the results changed very little when the smooth functions for long-term time trend and within-summer seasonal variation were relaxed. However, the variation in the year-specific heat estimates increased to some extent. Generally, the air pollution variables were not included as

\begin{tabular}{|c|c|c|c|c|c|}
\hline TOT & $0.65(0.17-1.14)$ & $0.71(0.28-1.15)$ & $-0.10(-0.20-0.04)$ & $0.19(-0.10-0.49)$ & $0.17(0.06-0.27)$ \\
\hline RES & $0.62(0.16-1.08)$ & $0.84(0.43-1.25)$ & $-0.19(-0.32--0.05)$ & $-0.12(-0.42-0.17)$ & $0.15(0.04-0.25)$ \\
\hline CVD & $0.74(0.27-1.21)$ & $0.88(0.32-1.16)$ & $-0.29(-0.48--0.10)$ & $-0.04(-0.35-0.26)$ & $0.16(0.05-0.27)$ \\
\hline CVD+RES & $0.79(0.32-1.27)$ & $0.88(0.46-1.31)$ & $-0.29(-0.49--0.10)$ & $-0.04(-0.34-0.26)$ & $0.16(0.05-0.26)$ \\
\hline
\end{tabular}

Data are presented as relative risk point estimate (95\% confidence interval). RH: relative humidity; TOT: total mortality; RES: respiratory mortality; INF: influenza mortality; CVD: cardiovascular mortality. The threshold corresponded to the 90th percentile of the 2-day mean summer temperature, $21.3^{\circ} \mathrm{C}$. 

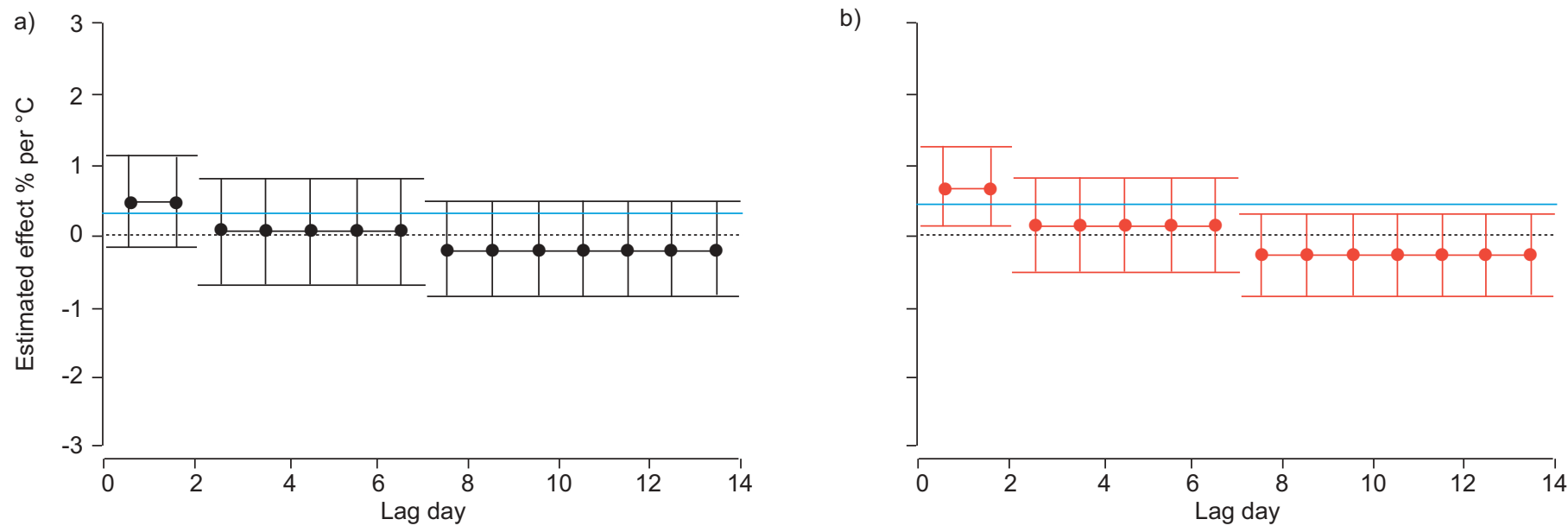

FIGURE 3. Lag-stratified distributed lags over the whole study period. a) Three estimates below the threshold and b) three estimates above the threshold. The vertical lines are $95 \%$ confidence intervals (Cls). Blue lines represent the cumulative effects over the 2 weeks studied: a) $0.30 \%$ per $\left.{ }^{\circ} \mathrm{C}(95 \% \mathrm{Cl}-0.88-1.50) ; \mathrm{b}\right) 0.45 \%$ per ${ }^{\circ} \mathrm{C}(95 \% \mathrm{Cl}$ $-0.59-1.51)$.
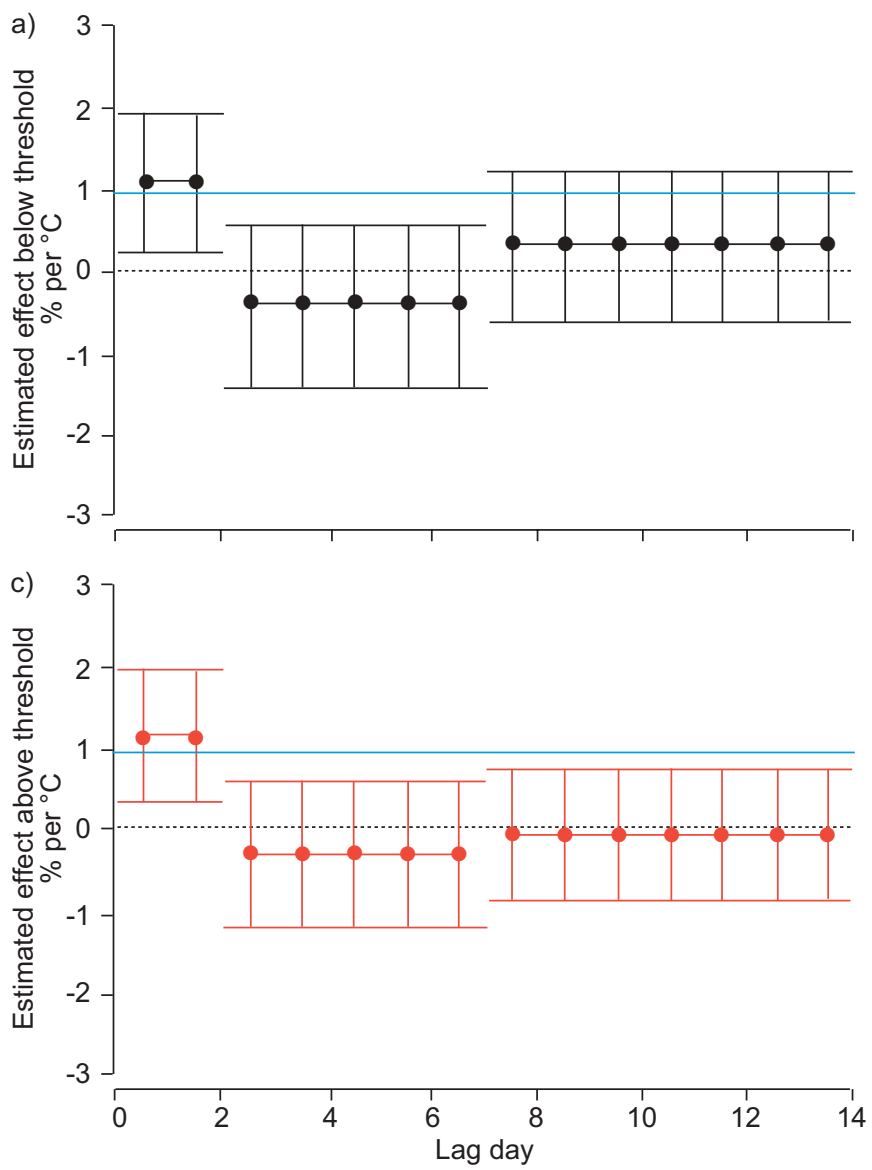

b)

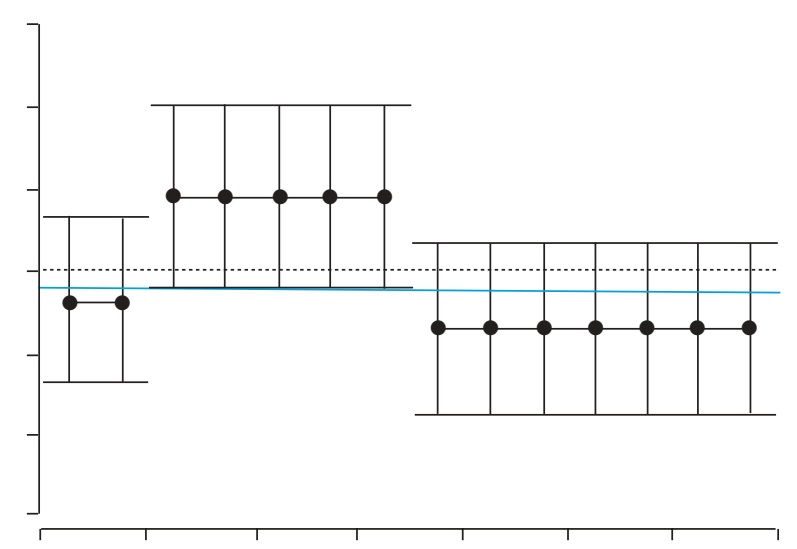

d)

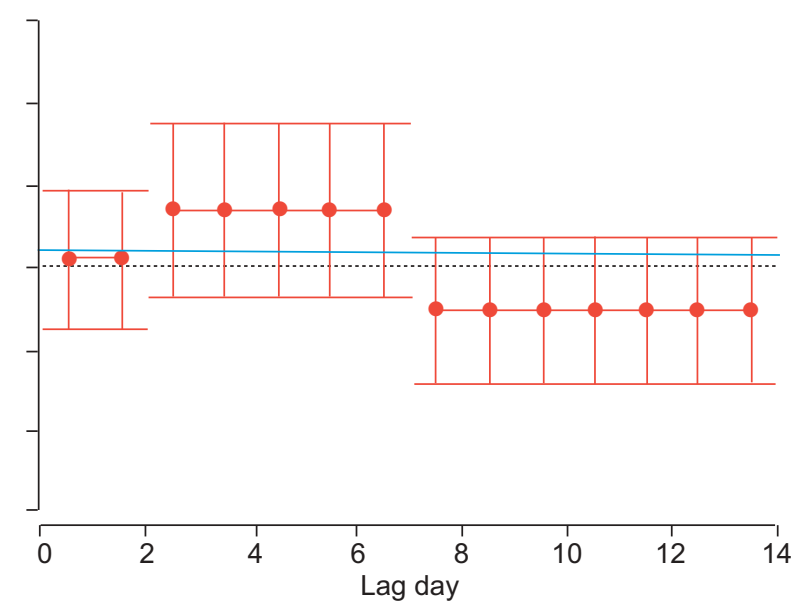

FIGURE 4. Effect estimates for the lag strata from the distributed lag model, as percentage increase in daily mortality per ${ }^{\circ} \mathrm{C}$ given for the association a and b) below and $c$ and d) above the threshold of 90th percentile and for summer following winters with low (a and c) and high ( $b$ and d) cardiovascular plus respiratory mortality. The vertical lines are $95 \%$ confidence intervals (Cls). Blue lines represent the cumulative effects over the 2 weeks studied: a) $0.95 \%$ per ${ }^{\circ} \mathrm{C}(95 \% \mathrm{Cl}-0.66-2.58)$; b) $-0.24 \%$ per ${ }^{\circ} \mathrm{C}(95 \% \mathrm{Cl}$ $2.02-1.56)$; c) $0.88 \%$ per ${ }^{\circ} \mathrm{C}(95 \% \mathrm{Cl}-0.52-2.31)$; d) $0.21 \%$ per ${ }^{\circ} \mathrm{C}(95 \% \mathrm{Cl}-1.37-1.01)$. The cumulative effects above and below threshold correspond to an increase in temperature of $1^{\circ} \mathrm{C}$ for 2 weeks above and below $21.3^{\circ} \mathrm{C}$, respectively. 
confounders in the presented models, since they had no significant effect $(p>0.1)$ on daily mortality in June-August.

\section{DISCUSSION}

To the current authors' knowledge, the present study is the first to show that the effect of temperature in summer depends significantly on the extent of the previous winter respiratory and cardiovascular mortality. According to the present study hypothesis, when the pool of fragile individuals is greater due to little cardiovascular and respiratory mortality in the previous winter, stronger and immediate effects of warmth are seen.

The general conclusion is that the dynamics and patterns of mortality in consecutive winters and summers are, to some extent, dependent on each other, related by the size of the pool of susceptible individuals. The present study has described some of the factors that affect the dynamics of the mortality pattern over the year and, more specifically, that the population in the fragile pool is subject to either general winter mortality or temperature-associated summer mortality. Also, the specific influenza mortality in winter showed a clear tendency to modify the effect of heat on mortality in summer. It can be assumed that far from all deaths related to influenza were classified as such. It may well be that high respiratory and/or high cardiovascular mortality behave fairly well as indicators for high influenza-related mortality. In fact, the correlation between the monthly number of deaths in respiratory mortality and influenza mortality in Stockholm during the study period was as high as 0.75 , while it was 0.44 between deaths in cardiovascular diseases and in influenza.

The observed effect modification and results from distributed lag models illustrate that there can be differences in the effect distribution and risk attributable population between years and may explain some of the inconsistency in the estimated mortality following heat exposure. These results showed a clear change in lag structure depending on whether there was a larger or smaller group of susceptible individuals. The somewhat more delayed effects when the pool was smaller after high cardiovascular plus respiratory mortality could reflect the fact that the victims of the heat were more resistant in those years. Some of the effects estimated in the distributed lag model did not reach significance but may still be seen as hypothesis generating. The level of statistical significance may rather be mostly a question of loss in power when introducing additional explanatory variables and splitting the data according to strata and threshold. It can be seen from the simple models that there was a significant effect of heat on mortality and, looking at the trend over the study period, it can also be seen that this effect is increasing. Judging by the decrease in winter cardiovascular mortality, the effects of summer temperatures in years to come would be expected to be larger and more immediate than in the early 1990s.

There have been intensive discussions about the role of mortality displacement from the 2003 heatwave, encouraged by the lower mortality levels the following years and the relatively low excess mortality during the 2006 heatwave [17]. As shown in the present study, the summer mortality was dependent on the extent of mortality in the winter season in a pool of susceptible individuals. Due to sharing of the fragile pool, the mortality during winter is most probably also dependent on the summer mortality. This dependency may also be influential over longer time-periods than the same year, but has not been subject to investigation in the current study.

A threshold of the heat effect in the summer was found at $21.3^{\circ} \mathrm{C}$ (for 2-day mean temperature), above which the increase was steeper. The use of a moving average of lag 0 and 1 of the daily mean temperatures was optimal in the sense of GCV score compared with longer lag times and minimum and maximum daily temperatures. It also described the cumulative effect estimates from the lag-stratified distributed lag models well. However, it might not explain the mortality as well as a specific heatwave indicator would, which would also take into account the prolongation of the heat event [21]. So far, Stockholm has been rather sparsely exposed to extreme heat events and, during the period studied, no serious heat events lasting several weeks were identified.

MEDINA-RAMÓN and SCHWARTZ [14] observed an absence of harvesting patterns for extreme temperatures, in contrast to less extreme temperatures. In the present study, the effect modification of previous winter season mortality was significant below the threshold, and did not show statistical significance above it. However, the lack of significant effect modification above the threshold, as well as the weak significance of mortality reductions and general effects below the threshold in the distributed lag models, might be subject to lower power when splitting the data according to a threshold (90th percentile), splitting the data by winter mortality strata and introducing additional variables.

Generally, 2 days with the mean temperature at $25^{\circ} \mathrm{C}$ and with mean $\mathrm{RH}$ of $80 \%$, compared with $16^{\circ} \mathrm{C}$ and mean $\mathrm{RH}$ of $68 \%$, would result in an immediate increase in the daily number of deaths of around $9 \%$ if respiratory mortality was low the previous winter, and of about $7 \%$ if respiratory mortality was high. With effect estimates from the distributed lag model, the difference would be far greater.

In the yearly variation of effect estimates, a significantly increasing time trend was seen. The trend was also apparent in models with threshold, both below and above the threshold. Therefore, it should not be due to the increase in temperatures over the period. However, the increased susceptibility over time could depend on demographics, disease prevalence or an increased use of influenza vaccines, leaving a larger pool of fragile individuals exposed to warm summer days. The proportion of elderly persons (aged >64 yrs) vaccinated against influenza by public healthcare centres increased from $38-58 \%$ in Stockholm during the short period from 1998-2001 (A. Örtqvist, County Medical Officer for Communicable Disease Control, Stockholm County; personal communication). During the previous period, 1990-1997, the current authors do not know what percentage of the population was vaccinated for influenza, but it is likely that the percentage increased through the whole study period. Therefore, influenza vaccinations in particular may have influenced the changing susceptibility to warm days, leaving a larger group of susceptible individuals for exposure. The significantly decreasing trend in the major cause of death, cardiovascular disease, in winter particularly, may also have contributed to a trend in the size of 
the susceptible pool, especially since the cardiovascular mortality seemed to decrease to a lesser extent during summer than during winter. It was not possible to estimate the change in fraction of elderly individuals over the study period. However, the general trends in mortality levels were accounted for in the models and, therefore, demographic factors such as the fraction of elderly persons in the population at a specific time were represented. Due to the observed time trend the overall estimates in the present study seem not to be representative for the population in Stockholm at the end of the study period or today.

Furthermore, a significant increase in summer mortality, independent of temperature, was seen when RH increased, but for the summer months no significant effects of the rather low levels of air pollution in Stockholm were found. However, interactive effects with air pollution that may be hard to detect due to the correlation with heat events, e.g. ozone-temperature effect modification, cannot be ruled out.

The evidence for displacement of death has been inconsistent in previously published studies on heat mortality [6-14]. For example, in heat-episode analysis the extent of the displacement of death is dependent on the occurrence time of the heat episode [13]. However, some of the variation in the short-term mortality displacement may be a consequence of harsh or mild winter mortality, as may the extent of excess mortality associated with a heatwave. These effect modification results highlight the need to use caution when interpreting risk for population-level mortality in time-series and episodes analyses. This is especially relevant when it comes to measures of years of life lost, which can be highly variable depending on the size of the population of fragile individuals at that particular time. The current results are of major interest when discussing the severity of heat mortality, since it is imperative to determine if and to what extent interventions can be expected to be effective as heatwave warning systems. Prior to the present study, the causes of the yearly variations in heat effect and mortality displacement had been poorly investigated. However, these variations are of great importance for describing the dynamics of mortality through the year and have implication far beyond the scope of heat effects on mortality.

\section{REFERENCES}

1 Ebi KL, Kovats RS, Menne B. An approach for assessing human health vulnerability and public health interventions to adapt to climate change. Environ Health Perspect 2006; 114: 1930-1934.

2 Kosatsky T. The 2003 European heat waves. Euro Surveill 2005; 10: 148-149.

3 McMichael AJ, Woodruff RE, Hales S. Climate change and human health: present and future risks. Lancet 2006; 367: 859-869.

4 Haines A, Kovats RS, Campbell-Lendrum D, Corvalan C. Climate change and human health: impacts, vulnerability, and mitigation. Lancet 2006; 367: 2101-2109.
5 Basu R, Samet JM. Relation between elevated ambient temperature and mortality: a review of the epidemiologic evidence. Epidemiol Rev 2002; 24: 190-202.

6 Braga AL, Zanobetti A, Schwartz J. The time course of weather-related deaths. Epidemiology 2001; 12: 662-667.

7 Fouillet A, Rey G, Laurent F, et al. Excess mortality related to the August 2003 heat wave in France. Int Arch Occup Environ Health 2006; 80: 16-24.

8 Hajat S, Armstrong BG, Gouveia N, Wilkinson P. Mortality displacement of heat-related deaths: a comparison of Delhi, Sao Paulo, and London. Epidemiology 2005; 16: 613-620.

9 Huynen MM, Martens P, Schram D, Weijenberg MP, Kunst AE. The impact of heat waves and cold spells on mortality rates in the Dutch population. Environ Health Perspect 2001; 109: 463-470.

10 Kaiser R, Le Tertre A, Schwartz J, Gotway CA, Daley WR, Rubin CH. The effect of the 1995 heat wave in Chicago on all-cause and cause-specific mortality. Am J Public Health 2007; 97: Suppl. 1, S158-S162.

11 Kyselý J. Mortality and displaced mortality during heat waves in the Czech Republic. Int J Biometeorol 2004; 49: 91-97.

12 Le Tertre A, Lefranc A, Eilstein D, et al. Impact of the 2003 heatwave on all-cause mortality in 9 French cities. Epidemiology 2006; 17: 75-79.

13 Rey G, Jougla E, Fouillet A, et al. The impact of major heat waves on all-cause and cause-specific mortality in France from 1971 to 2003. Int Arch Occup Environ Health 2007; 80: 615-626.

14 Medina-Ramón M, Schwartz J. Temperature, temperature extremes, and mortality: a study of acclimatisation and effect modification in 50 US cities. Occup Environ Med 2007; 64: 827-833.

15 Armstrong B. Models for the relationship between ambient temperature and daily mortality. Epidemiology 2006; 17: 624-631.

16 Pirard P, Vandentorren S, Pascal M, et al. Summary of the mortality impact assessment of the 2003 heat wave in France. Euro Surveill 2005; 10: 153-156.

17 Fouillet A, Rey G, Wagner V, et al. Has the impact of heat waves on mortality changed in France since the European heat wave of summer 2003? A study of the 2006 heat wave. Int J Epidemiol 2008; 37: 309-317.

18 Michelozzi P, de Donato F, Bisanti L, et al. The impact of the summer 2003 heat waves on mortality in four Italian cities. Euro Surveill 2005; 10: 161-165.

19 Simón F, Lopez-Abente G, Ballester E, Martínez F. Mortality in Spain during the heat waves of summer 2003. Euro Surveill 2005; 10: 156-161.

20 Frost DB, Auliciems A. Myocardial infarct death, the population at risk, and temperature habituation. Int $J$ Biometeorol 1993; 37: 46-51.

21 Rocklöv J, Forsberg B. The effect of temperature on mortality in Stockholm 1998-2003: a study of lag structures and heatwave effects. Scand J Public Health 2008; 36: 516-523. 